\title{
Estimation of Lead Acid Battery Capacity using Pulse Voltammetry Cyclic and Neural Network Method
}

\author{
Bambang Sri Kaloko \\ Lecturer of Electrical \\ Engineering \\ Faculty of Engineering \\ Jember University, Jember, \\ Indonesia
}

\author{
Suprihadi Prasetyono \\ Lecturer of Electrical \\ Engineering \\ Faculty of Engineering \\ Jember University, Jember, \\ Indonesia
}

\author{
Lori Kusuma Dewi \\ Student of Electrical \\ Engineering \\ Faculty of Engineering \\ Jember University, Jember, \\ Indonesia
}

\begin{abstract}
The requirement for a reliable battery that holds a very important role. Therefore, this study refers to the characterization of lead acid batteries, this type is a secondary battery of the most developed and the lead acid batteries are widely used in the automotive field. The lead acid battery capacity is determined by the amount of electrical charge that is obtained from the battery and the amount depends on the active ingredient contained in the plate. To determine the characterization and capacity lead acid battery is good and suitable for use, this study used two methods. There are voltammetry analysis and development the lead acid battery model design based on neural network method. In the electrochemical field the voltammetry cyclic is a condition when the current is measured during a sweep potential from the beginning to the end potential and then back again. It is also called sweeping or scanning and can be reversed after the reduction takes. So the anodic and cathodic current can be measured. Then the design of the model development lead acid battery based on neural network in this study using inputs spesifically the voltage as input, and the current as target. So the accuracy testing of the forecasting system using neural network algorithm will be better and more efficient than the experiment data manually.
\end{abstract}

\section{Keywords}

Lead Acid Battery, Neural Network, Voltammetry cyclic.

\section{INTRODUCTION}

Lead acid batteries are widely used for automotive applications, and called battery as well as SLI (Starting, Lightning and Ignition). The types of SLI batteries are used because the material to make these batteries is quite cheap but the battery has a great performance. However, for applications requiring higher power with a relatively long time, SLI batteries can't be used. This is because lead acid batteries only have a depth of electrostatic discharge (Depth of Discharge DOD) by $50 \%$ only [7].

Lead acid batteries are composed of lead dioxide as the cathode, a metal sponge as the anode lead and sulfuric acid as the electrolyte. Each cell has a voltage of 2 volts. Advantages of the use of lead acid batteries which are robust, inexpensive, reliable, tolerant of excess charging, low internal impedance. While the lack of a battery of this type which are very heavy, have low energy efficiency of about $70 \%$, dangerous overheating during charging, have a lower cycle time is $300-$ 500 cycles, and materials are harmful to the environment [1].

With these descriptions, the authors will discuss about Estimation Capacity of Lead Acid Batteries By Pulse Voltammetry And Based On Neural Network Method [2]. The purpose to determine the capacity of a lead acid battery is great and suitable for use. And also to know how to increase the capacity of lead acid batteries with a constant voltage, so we get more efficient lead acid battery [8].

\section{EXPERIMENTAL PROCEDURE}

The lead acid batteries will measuring and appliying on Pulse Voltammetry cyclic method. In this voltammetry measurement, the working electrode use a pure $\mathrm{Pb}$ sheet. In order to remove the oxide layer of the $\mathrm{Pb}$ electrode, Voltammetry cycles. H2SO4 were carried out for several times. It was directly used as the negative electrode. As the positive electrode, were carried out to form the $\mathrm{PbO} 4$ layer. The counter electrode was a piece of the $\mathrm{Pb}$ or $\mathrm{PbO} 2$ electrode cut from the practical battery. Cyclic Voltammetry was carried out in $\mathrm{H} 2 \mathrm{SO} 4$ solutions using a conventional potentiostat and a function for negative electrodes positive electrodes.

Then, the data of measurement will be appliying in to neural network method. Design of the model development lead acid battery based on neural network in this study using current and voltage. So the accuracy testing of the forecasting system using neural network algorithm will be better and more efficient than the experiment data manually.

\section{RESULTS AND DISCUSSION}

Cyclic voltammetry is a technique used to obtain qualitative information about the electrochemical reaction. Cyclic voltammetry is a method of measuring electrochemical potentiodynamic potential waveform used in electrochemical analysis is a linear waveform, the potential is continuously changed as a linear function of the time. Cyclic voltammetry measurement results can be used to determine the thermodynamic properties of redox processes, kinetic properties of electron transfer reactions and adsorption reaction.

Voltammetry cell consists of a working electrode, auxiliary electrode, and a reference electrode immersed in the cell where three voltammetry containing the sample solution. Potential outside (V), is applied between the working electrode and a reference electrode to produce current. In this study used as the working electrode $\mathrm{PbO} 2$ and $\mathrm{Pb}$ as electrode comparison with $\mathrm{H} 2 \mathrm{SO} 4$ as the electrolyte. In this experiment did not use the auxiliary electrode because electrode $\mathrm{PbO} 2$ and $\mathrm{Pb}$ easy to react. So that the measurement electrodes $\mathrm{PbO} 2$ and $\mathrm{Pb}$ using a potentiostat with cyclic voltammetry method shows a graph like Fig.1.

Then the data that have been obtained using cyclic voltammetry measurements as a target on the application of neural network method using Software Matlab. At the moment there are training regression, outputs and targets using linear regression, regression is measuring two or more 
variables are expressed as a relationship form or function. To determine the kind of relationship or regression needed their unequivocal separation between independent variables by the $\mathrm{X}$ symbol and the independent variable by the $\mathrm{Y}$ symbol. From Fig. 2 obtained equation of the line to get the best match for Output $=\mathrm{T}+(-0.00011)$ with a correlation coefficient equal to 1 and gradien best line of 1 , it shows the value of a very good result for a match with the target output value.

Fig. 5 shows when data is the result of the measurement using cyclic voltammetry with the voltage (E) as input and current (I) as a target. To applying a voltage different from the voltage of -0.5 Volts to 1.5 Volts to produce different currents. Thus it can be seen on the voltage how currents are the maximum values. While in Fig. 6 is the result of current output after simulated using the neural network in Matlab
Software with the same voltage input data cyclic voltammetry.

On the Fig. 4 the data of voltammetry measurement was generated at the simulation diagram on software matlab. With input matrik 1 X 21 data and the target matrik 1 X 21 data. With the simulations diagram, we can show value current of the output on display when we insert the value of voltage on constant side. And then, data neural network simulation can be show at Table. 1. By comparing the results of simulated neural network with cyclic voltammetry testing method, then there is a difference, and that difference is the error that occurred. If the smaller error value are better than biger value. Data results from the simulation comparison neural network with cyclic voltammetry testing methods can be seen from Table. 1 and Fig. 7 as follows.

Table 1. Comparison resul of voltammetry and neural network data.

\begin{tabular}{|c|c|c|c|c|}
\hline No. & $\mathrm{E}(\mathrm{V})$ & $\mathrm{I}(\mu \mathrm{A})$ Voltammetry & $\mathrm{I}(\mu \mathrm{A}) \mathrm{NN}$ & Error = I Voltammetry- I NN \\
\hline 1 & -0.5 & -0.00033 & -0.00032 & -0.00001 \\
\hline 2 & -0.4 & 0.00774 & 0.00773 & 0.00001 \\
\hline 3 & -0.3 & 0.0175 & 0.01755 & -0.00005 \\
\hline 4 & -0.2 & 0.02135 & 0.02123 & 0.00012 \\
\hline 5 & -0.1 & 0.02277 & 0.02290 & 0.00013 \\
\hline 6 & 0 & 0.02359 & 0.02360 & -0.00001 \\
\hline 7 & 0.1 & 0.02425 & 0.02424 & 0.00001 \\
\hline 8 & 0.2 & 0.02391 & 0.02400 & -0.00009 \\
\hline 9 & 0.3 & 0.02337 & 0.02324 & 0.00013 \\
\hline 10 & 0.4 & 0.02035 & 0.02036 & 0.00009 \\
\hline 11 & 0.5 & 0.01639 & 0.01644 & -0.00005 \\
\hline 12 & 0.6 & 0.01352 & 0.01368 & -0.00016 \\
\hline 13 & 0.7 & 0.01278 & 0.01257 & 0.00021 \\
\hline 14 & 0.8 & 0.01197 & 0.01204 & -0.00007 \\
\hline 15 & 0.9 & 0.01108 & 0.01114 & -0.00006 \\
\hline 16 & 1 & 0.01014 & 0.01008 & 0.00006 \\
\hline 17 & 1.1 & 0.00930 & 0.00929 & 0.00001 \\
\hline 18 & 1.2 & 0.00838 & 0.00841 & -0.00003 \\
\hline 19 & 1.3 & 0.00732 & 0.00729 & 0.00003 \\
\hline 20 & 1.4 & 0.00647 & 0.00647 & 0 \\
\hline & & & & \\
\hline
\end{tabular}

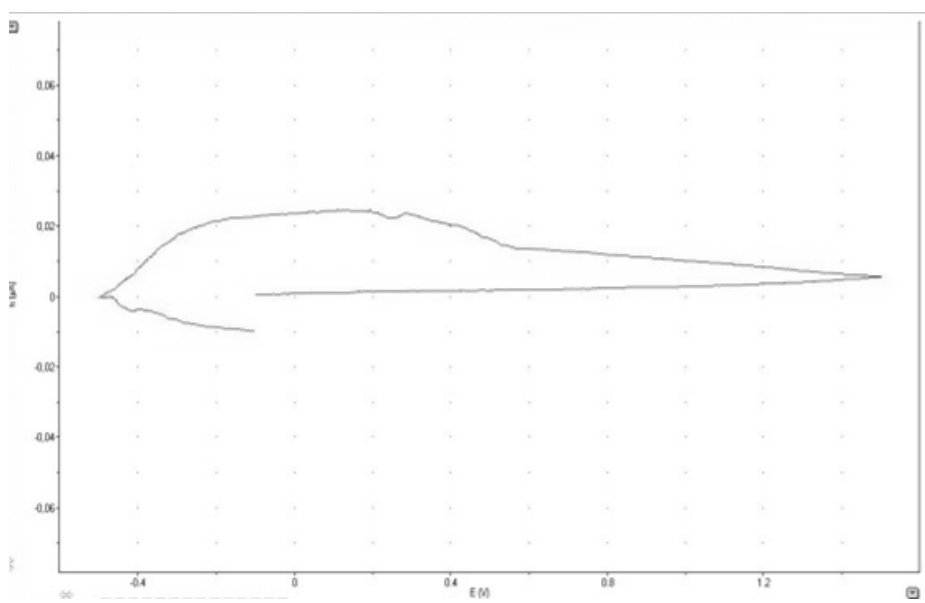

Fig 1: the measurement electrodes $\mathrm{PbO} 2$ and $\mathrm{Pb}$ using a potentiostat with cyclic voltammetry method 


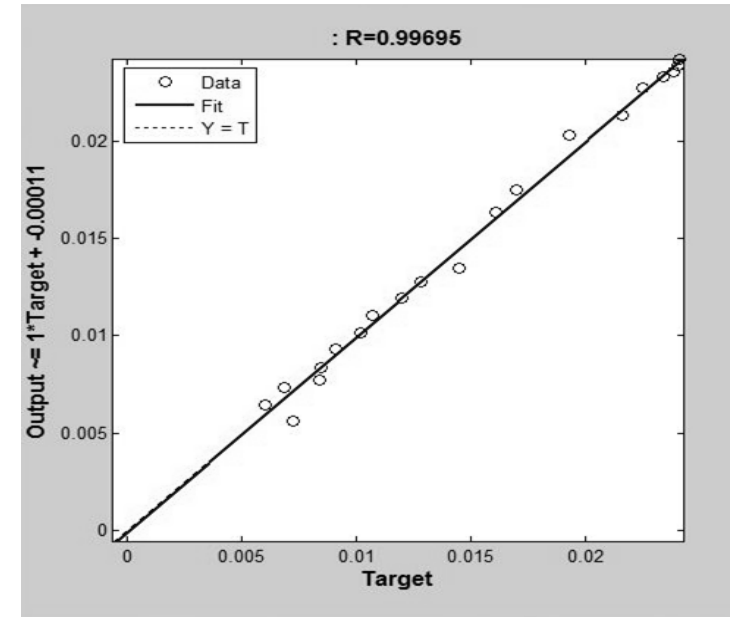

Fig 2: plot regression

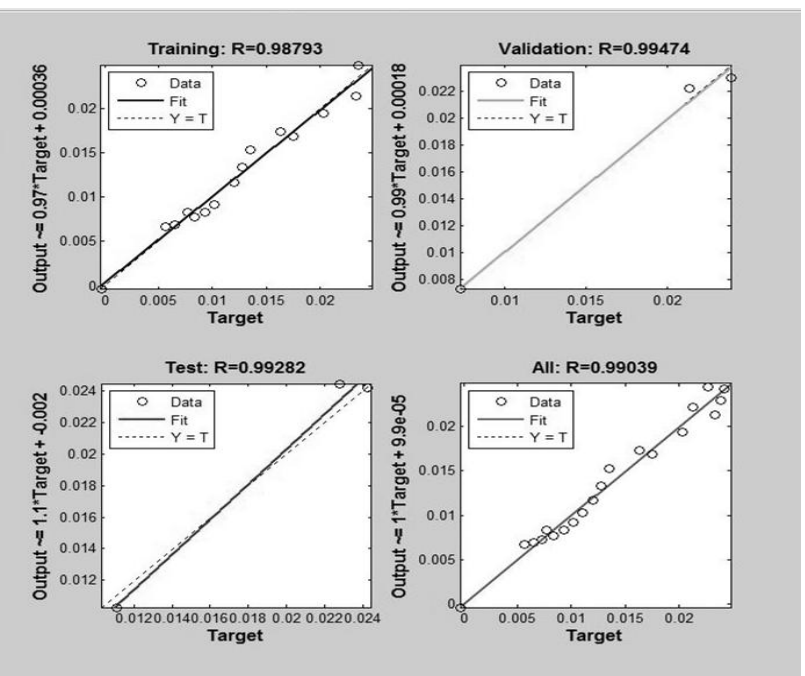

Fig 3: plot regression on training mode neural network

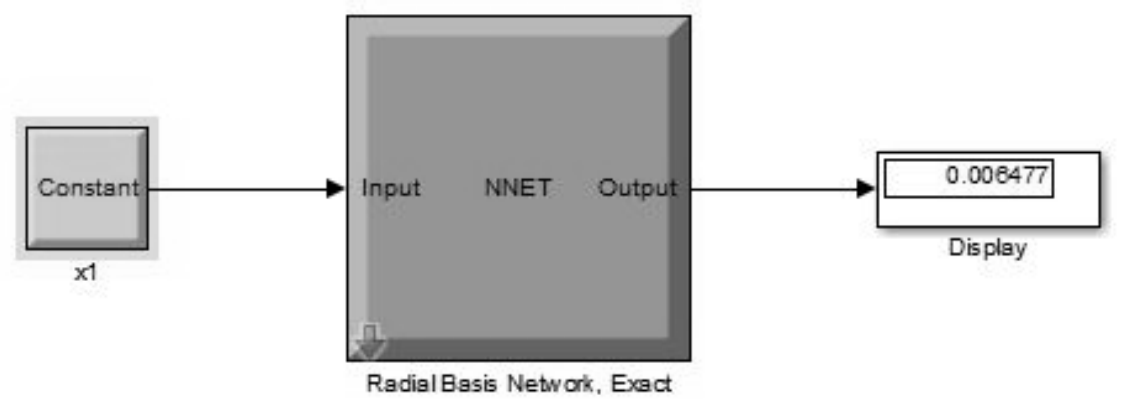

Fig 4: The Neural Network Simulation Diagram on Software Matlab

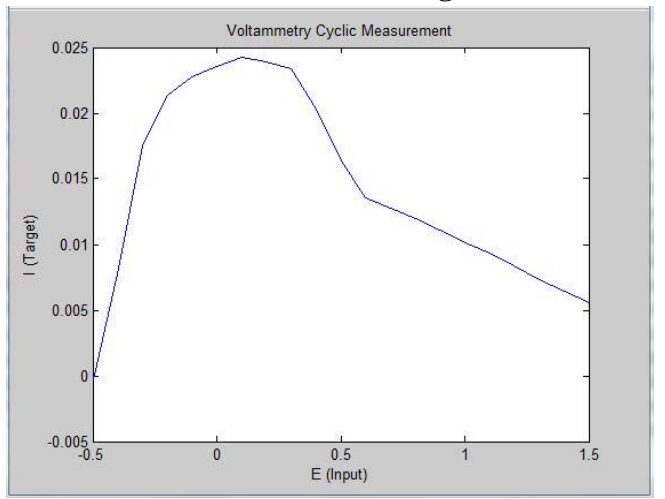

Fig. 5 voltammetry cyclic as target graph on Mathlab 


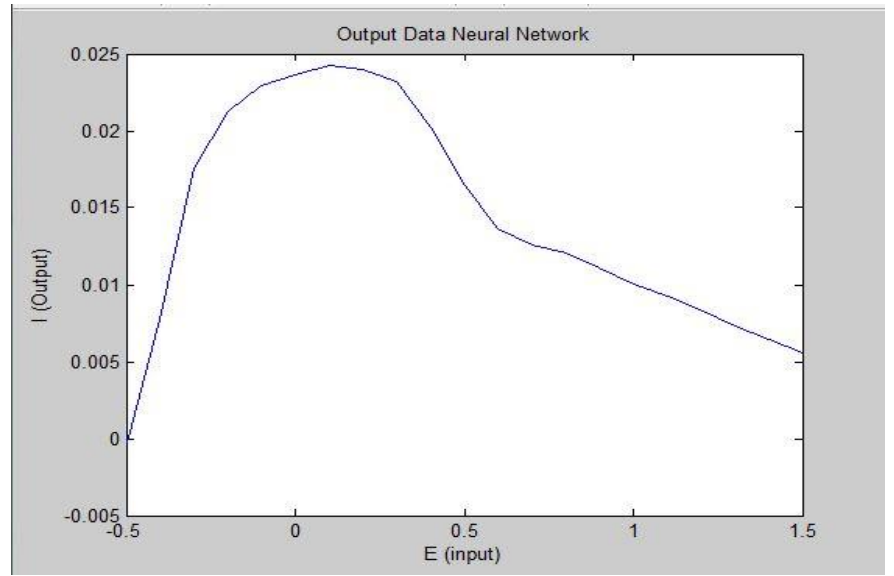

Fig 6: result of neural network graph on Mathlab

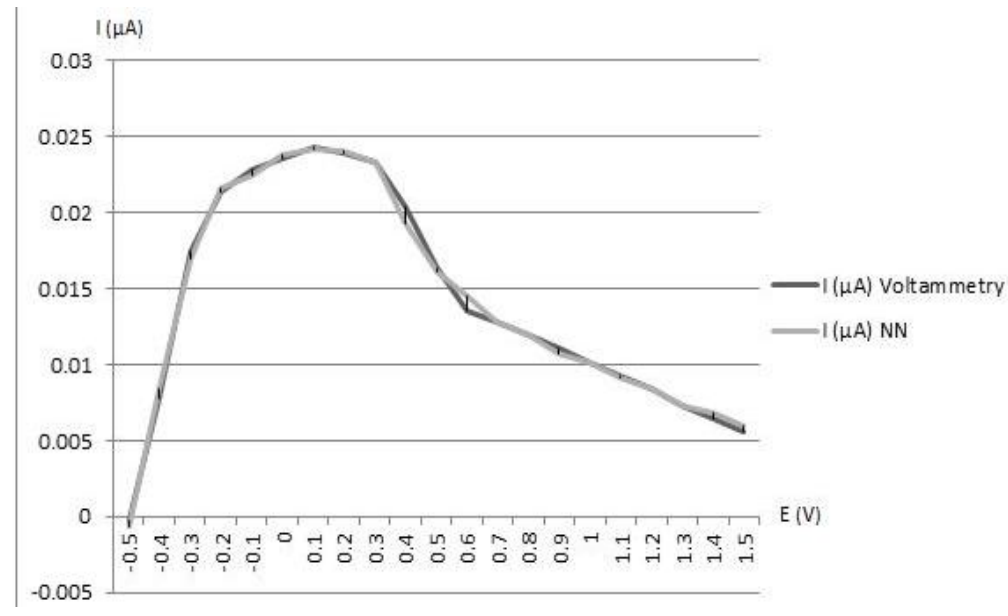

Fig 7: comparison result of voltammetry and neural network data.

\section{CONCLUSION}

On research testing battery capacity by sample electrode $\mathrm{Pb}$ and $\mathrm{PbO} 2$ it can be seen the value of a maximum current is obtained that is equal to $0.02425 \mu \mathrm{A}$ with a voltage of 0.1 volts on testing by the method of cyclic voltammetry and a maximum current of $0.02424 \mu \mathrm{A}$ with voltage 0.1 Volt simulated neural network. The minimum or smallest current is obtained that is equal to -0.00033 with a voltage of -0.5 Volts on testing by voltammetry cyclic method and a minimum current of -0.00032 with voltage -0.5 Volts simulated with neural network. Then the results of the two methods produce the difference is called the error and the biggest error that occurred in the data contained all 13 at $0.00021 \mu \mathrm{A}$ at a voltage 0.4 Volts and the smallest error contained in the data to 20 th at 0 at a voltage 1.4 Volts.

\section{ACKNOWLEDGEMENTS}

This research was supported by grant of Higher Education Programe. I would like to express my thanks to everyone who helped me faithfully to finish the job. I would also like to thank the reviewers who gave very useful suggestions which help me improve the quality of research.

\section{REFERENCES}

[1] IKEDA, S., OKA, H., Mori, Y., MAEDA, M., OHTA, M., ONO, S., et al. (2003). Effects of Additives on Positive and Negative Electrodes of Lead-Acid Batteries.

[2] Lahoucine Atourki, E. h. (2014). Characterization of ZnO Thin Films Grown by Linear Sweep.

[3] M. Sugawara, e. (2003). ITE Lett., 4 (4), 424.

[4] Potocnik, P. (2012). Neural Networks: MATLAB examples. University of Ljubljana : MATLAB ${ }^{\circledR}$ 7.14.

[5] S.B. Jambure, S. P. (2014). A comparative study of physico-chemical properties of CBD and SILAR grown $\mathrm{ZnO}$ thin films. Materials Research Bulletin.

[6] Wang Sicheng, C. Z. (2005). SOC Moeling For Leadacid Battery And Developments Of SOC On-line Tester[J]. ACTA ENERGIAE SOLARIS, 26(1):6-13.

[7] WANG Zhiguo, G. Y. (2003). Research on the Equivalent Circuit Model of Lead-Acid Battery. Journal of Armed Force Engineering Institude, 17(1):78-81.

[8] Xiyun Yang, F. J. (2013). Prediction of Lead-acid Storage Battery's Remaining Capacity Based on LM-BP. IEEE. 